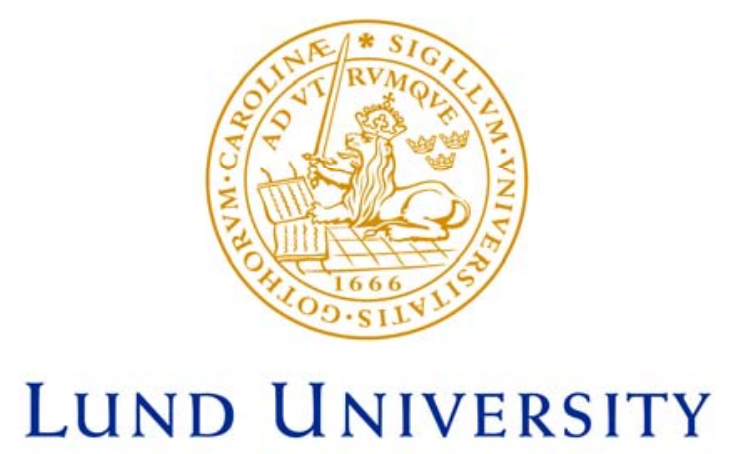

Faculty of Medicine

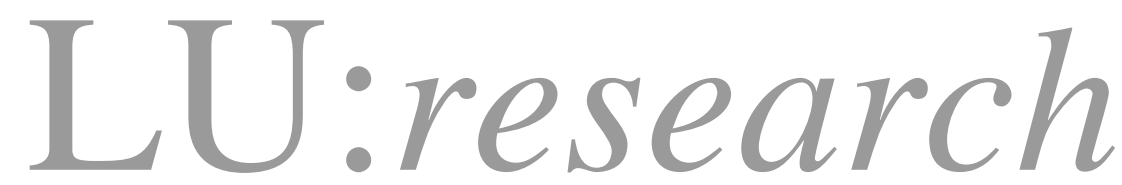

Institutional Repository of Lund University

This is an author produced version of a paper published in Epilepsia. This paper has been peer-reviewed but does not include the final publisher proof-corrections or journal pagination.

Citation for the published paper:

Hallbook, Tove and Lundgren, Johan and Rosén, Ingmar. "Ketogenic diet improves sleep quality in children with therapy-resistant epilepsy"

Epilepsia, 2007, Vol: 48, Issue: 1, pp. 59-65.

http://dx.doi.org/10.1111/j.1528-1167.2006.00834.x

Access to the published version may require journal subscription.

Published with permission from: Blackwell Science 


\title{
Ketogenic Diet Improves Sleep Quality in Children with Therapy Resistant Epilepsy
}

\author{
Tove Hallböök ${ }^{1}$, Johan Lundgren ${ }^{1}$, Ingmar Rosén ${ }^{2}$ \\ Department of Clinical Sciences, Lund, Divisions of ${ }^{1}$ Paediatrics and ${ }^{2}$ Clinical \\ Neurophysiology, University Hospital, Lund, Sweden
}

Key Words: sleep, REM sleep, slow wave sleep, children, epilepsy, ketogenic diet, EEG, quality of life, attention, behaviour

Correspondence to: Dr. Tove Hallböök, Division of Paediatrics, University Hospital, SE-221 85 Lund, Sweden. E-mail: tove.hallbook@skane.se 


\section{Purpose}

The study purpose was to evaluate sleep structure during ketogenic diet (KD) treatment in children with therapy resistant epilepsy and to correlate possible alterations with changes in clinical effects on seizure reduction, seizure severity, quality of life (QOL) and behaviour. Methods

Eighteen children were examined with ambulatory polysomnographic recordings initially and after three months of KD treatment. Eleven children continued with the KD and were also evaluated after 12 months. Sleep parameters were estimated. Seizure frequency was recorded in a diary and seizure severity in the National health seizure severity scale (NHS3). QOL was assessed with a visual analogue scale. Child Behaviour Checklist and Ponsford and Kinsella’s Rating-Scale of Attentional Behaviour were used.

Results

KD induced a significant decrease in total sleep $(\mathrm{p}=0.05)$ and total night sleep $(\mathrm{p}=0.006)$. Slow wave sleep was preserved, rapid eye movement (Bailey and Bremer) sleep increased $(p=0.01)$, sleep stage two decreased $(p=0.004)$ and sleep stage one was unchanged. Eleven children continued with the KD and were also evaluated after 12 months. They showed a significant decrease in daytime sleep $(\mathrm{p}=0.01)$ and a further increase in REM sleep $(\mathrm{p}=0.06)$. Seizure frequency $(\mathrm{p}=0.001, \mathrm{p}=0.003)$, seizure severity $(\mathrm{p}<0.001, \mathrm{p}=0.005)$ and $\mathrm{QOL}$ $(\mathrm{p}<0.001, \mathrm{p}=0.005)$ were significantly improved at three and twelve months. Attentional behaviour was also improved, significantly so at three months $(\mathrm{p}=0.003)$. There was a significant correlation between increased REM sleep and improvement in QOL (Spearman r= $0.6, \mathrm{p}=0.01$ ) at three months. 


\section{Conclusion}

Ketogenic Diet decreases sleep and improves sleep quality in children with therapy resistant epilepsy. The improvement in sleep quality, with increased REM sleep, seems to contribute to the improvement in QOL. 
Introduction

Ketogenic diet (KD) is a high fat, low carbohydrate and low protein diet that has been used for childhood therapy resistant epilepsy since the 1920s. It was developed to mimic the ketotic state of starvation (Geyelin, 1921, Wilder, 1921). A standard approach to KD treatment includes a 2-year diet period with a 6- to 12- months wean (Freeman et al., 1994). Fasting and fall in blood glucose reduces plasma insulin production and stimulates lipolysis and production of fatty acids. Fasting is also up-regulating the MCT-1, monocarboxylic transport system of ketone bodies to the brain. Ketone bodies can pass directly into the neuronal mitochondria. Once in the mitochondria, beta-hydroxybutyrate is converted to acetoacetate and acetoacetate-CoA for the ATP production in the tricarboxylic acid cycle. Efficacy and safety have been demonstrated in several studies. At least $50 \%$ of children with therapy resistant epilepsy achieve more than a 50\% reduction in seizure frequency (Freeman et al., 1998, Lefevre and Aronson, 2000). The reported improvement in attention, cognition and behaviour seems to be unrelated to the level of attained seizure control (Pulsifer et al., 2001). The basis for the improvement in both seizure control and behaviour is still unclear. There are different theories of the anti epileptic mechanisms of ketogenic diet. Increased cerebral energy reserves with decreased ictal excitability, decreased rate of glutamate transamination to aspartate and, possibly, enhancement in the rate of glutamate decarboxylation to GABA, may be some of the important mechanisms behind the increased resistance to seizures in ketotic brain tissue in response to starvation or KD (Schwartzkroin, 1999, Stafstrom and Rho, 2004). The effects of KD on sleep have not yet been elucidated as far as we know. Patients with frequent or medically intractable seizures have multiple sleep abnormalities including increased latency to sleep onset, increased number and duration of awakenings, decreased sleep efficiency, increased number of stage shifts and decreased or fragmented rapid eye 
movement (REM) sleep (Ohayon et al., 2004, Touchon et al., 1991). Inadequate sleep can exacerbate daytime-drowsiness, memory dysfunction, defective attention and behavioral problems thus affect quality of life (QOL) (Mendez and Radtke, 2001). Influences of sleep on epilepsy are also well known. The different sleep stages have a different effect on interictal discharge production. In non REM sleep, particularly in sleep stage two, a synchronizing effect is shown with an increase and a spreading of the interictal abnormalities and seizures. In contrast, REM sleep, with its asynchronous cellular discharge patterns and skeletal motor paralysis, increases the resistance to propagation of epileptic EEG discharges and to clinical motor accompaniment (Bazil, 2003, Crespel et al., 2000, Shouse et al., 1996).

The study purpose was to evaluate sleep structure following KD in children with therapy resistant epilepsy and to correlate possible alterations with changes in clinical effects on seizure reduction, seizure severity, QOL, attention and behaviour. This study includes all children put on KD from December 1999. The first 18 children are presented in this study. 
Methods

\section{Subjects}

Eighteen children (nine boys and nine girls) aged 2 -15 years (median 7.5 years) with the diagnosis of therapy-resistant epilepsy with developmental impairment, and absence of nonepileptic seizures or specific sleep disorders were started on KD. Epilepsy surgery had been performed in one patient (\# 4) and found not applicable in the others. Additional clinical features of the patients are given in Table 1 . All children were controlled in the same epilepsy center with the same KD-nurse. Patients remained on stable anti-epileptic drug medication for at least three months prior to the KD initiation and during the follow up. Plasmaconcentrations of anti epileptic drugs (AED) were taken every third month and found not changed. Written informed consent was obtained. The study was accepted by the Ethics Committee of the Faculty of Medicine of the Lund University.

Ketogenic Diet

All children were admitted to the hospital and started gradually on the diet following a 12hour out patient fast. The children were started on the classical KD. Fifteen received a 4:1 and three a 3.5:1 ratio implying $4 \mathrm{~g}$ or $3.5 \mathrm{~g}$ of fat to $1 \mathrm{~g}$ of combined protein and carbohydrates. Sixteen children were kept stable and two more changed from ratio 4:1 to 3.5:1 during the first three months and were then kept stable. The children also received the recommended daily intake of vitamins and minerals and were supplemented with calcium, magnesium, phosphorous, potassium and carnitine. The children were closely monitored to exclude intake of extra carbohydrates. In two children the diet was introduced via a gastrostomy tube, using Ketocal and a soy milk based ketogenic formula. 
Polysomnographic recordings

Ambulatory polysomnographic recordings (PSG) with the children in their natural surroundings were performed initially and after three and twelve months of KD treatment. The Embla A10 Flaga-Medcare digital data recorder, using sampling rate $200 \mathrm{~Hz}$ with 16 bits resolution was used. The digitalized data was transferred to Somnologica 3.1 (Flaga hf. Medical Devices) for PSG analysis. Sleep parameters were scored according to Rechtschaffen and Kales criteria (Rechtschaffen and Kales, 1968) both automatically and manually. We used the Somnologica automatic sleep scoring hypnogram with necessary corrections for overestimated slow wave sleep (SWS) and underestimated REM sleep. Sleep stage 3 and 4 were treated together as SWS.

Monitoring

During three months before KD initiation, a diary of seizure frequency and severity was collected together with clinical data. The severity of the seizures was scored with the National Hospital Seizure Severity Scale (NHS3), a further development of the Chalfont Seizure Severity Scale described by O’Donoghue et al (O'Donoghue et al., 1996). QOL was assessed with a visual analogue scale and parents' perception of the children's general behaviour and attention were quantified by using the total score of the Child Behaviour Checklist (CBCL) (Achenbach, 1991) and Ponsford and Kinsella’s rating scale of attentional behaviour (Ponsford and Kinsella, 1991). Follow-up assessments were performed after three and twelve months of KD.

\section{Statistical Evaluation}

Wilcoxon signed rank test was used for comparison of data from the hypnogram. Median time in minutes and percent of total night sleep were analysed in REM sleep, sleep stage one, sleep stage two and SWS, initially and after three and twelve months of KD treatment. Wilcoxon signed rank test was also used for comparison of the clinical data on seizure frequency, 
seizure severity, QOL, attention and behaviour before KD initiation and three and twelve months later. Spearman rank correlation coefficient (r) was used to calculate the correlation in degree of improvement between sleep parameters and clinical effects. The level of significance was set at $\mathrm{p}<0.05$. 
Results

\section{Sleep scoring}

KD induced a significant decrease in total sleep $(\mathrm{p}=0.05)$ and total night sleep $(\mathrm{p}=0.006)$. SWS was preserved, REM sleep increased ( $\mathrm{p=0.01)}$ (Fig. 1 and 2), sleep stage two decreased $(\mathrm{p}=0.004)$ and sleep stage one was unchanged. Eleven children continued with the KD and were also evaluated after 12 months. They showed a significant decrease in daytime sleep $(p=0.01)$ and a further increase in REM sleep $(p=0.06)$. The medians and ranges of PSG sleep variables are shown for all 18 children, initially and after three months of KD in Table 2 and for the 11 children that continued, initially and after three and 12 months of KD in Table 3. Median and range of the beta hydroxybutyrate levels initially and after three and 12 months in the two groups are also shown in Table 2 and 3.

\section{Monitoring}

At three months there was a significant reduction in seizure frequency $(\mathrm{p}=0.001)$. Eight children (44\%) showed $90 \%$ or more reduction in seizure frequency, four (22\%) became seizure free, four (22\%) had a 50-90\% seizure reduction, five (28\%) less than $50 \%$ seizure reduction and one (6\%) increased in seizure frequency. Eleven children (61\%) continued with the diet. They were also evaluated after 12 months. They had a significant reduction in seizure frequency $(\mathrm{p}=0.003)$. Four $(36 \%)$ had a $90 \%$ or more reduction of seizures, two $(18 \%)$ were seizure free, four (36\%) had a 50-90\% seizure reduction and three (27\%) less than $50 \%$ seizure reduction.

Seizure severity and QOL were significantly improved at three and twelve months $(\mathrm{p}<0.001$, $\mathrm{p}=0.005$ ). Attentional behaviour was also improved, significantly so at three months $(p=0.006, p=0.08)$. Changes in sleep parameters were compared with clinical seizure reduction, improvement in seizure severity, attentional behaviour and QOL. There was a 
significant correlation between increased REM sleep and improvement in QOL at three months (Spearman $r=0.6, p=0.01$ ). No other significant correlations were seen. The three children that continued KD despite less than 50\% seizure reduction described an improvement in seizure severity, a decrease in total sleep and an improvement in attentional behaviour and QOL. One of the three children that stopped the KD despite good antiepileptic effect experienced ataxia and lethargy. These side effects overweighed the antiepileptic effect. In the other two there were problems with compliance. 


\section{Discussion}

In this study we saw decreased total sleep (TS) and total night sleep (TNS) and at 12 months a decreased total daytime sleep (TDS). REM sleep increased, sleep stage two decreased and SWS was preserved. We also saw an improvement in seizure frequency, seizure severity, attentional behaviour and QOL.

To avoid first night laboratory effects the recordings were performed ambulatory with the children in their natural surroundings. PSG was performed on the left side. In a few children the right side was used because of artifacts from a lose lead or because of abundant epileptiform activity. All PSG recordings were interpretable with the Somnologica automatic sleep scoring hypnogram with necessary corrections manually for overestimated SWS and underestimated REM sleep. AED were kept stable throughout the study. The good antiepileptic effect and a slight fall off in efficacy during the study could justify this. On the other hand, despite a good antiepileptic effect or even seizure freedom we did not reduce or taper the AED until 12 months. This is in accordance with the recommendations after epilepsy surgery, where AED are kept stable for at least one year.

The changes in sleep parameters cannot solely be explained by age dependent changes. Total sleep time does not change with age from early childhood to adolescence. It is related to environmental factors rather than biologic changes. At birth the amount of REM and non REM sleep is about equal. The amount of REM sleep gradually decreases to $20-25 \%$ before the age of five. There are no significant changes in REM sleep with age from 5 years of age or older. SWS decreases during childhood and this continues steadily until old age. The amount of sleep stage two increases with age from early childhood (Borbely and Achermann, 1999, Finelli et al., 2001, Ohayon et al., 2004). Sleep is strongly influenced by epilepsy and seizures. Sleep disturbances are common in patients with epilepsy (Bazil, 2003, Mendez and 
Radtke, 2001). Altered sleep organization and microarchitecture with increased awakenings during sleep, decreased sleep efficiency, decreased and fragmented REM sleep and increased sleep stage two is seen (Ohayon et al., 2004, Touchon et al., 1991). Cortesi et al showed in a study on 89 children with idiopathic epilepsy that children with epilepsy had more sleep problems and decreased QOL than controls (Cortesi et al., 1999). In an earlier study we presented sleep changes after VNS-treatment in a group of 15 children with therapy resistant epilepsy and cognitive impairment. These children exhibited similar sleep disturbances before treatment and showed similar benefits on sleep architecture with decreased TS, TNS and TDS and an increase in REM sleep and a significant increase in SWS (Hallbook et al., 2005). In this study we see a normalization of abnormal sleep patterns in most of the children. Initially, TS, TNS and TDS are pathologically increased, REM sleep is decreased, sleep stage two and the number of sleep stage shifts are increased. The increase in REM sleep seems to be a normalization of the initially pathologically decreased percentage of REM sleep. The decreased TS, TNS and TDS, seen in our study, are probably due to the improved sleep structure and sleep quality including increased REM sleep, decreased sleep stage two and preserved SWS, following KD. We infer that the increased REM sleep is an important marker for improved sleep quality. This was significantly correlated to the improved QOL. Sleep is also known to have both precipitating and protecting effects on seizures. Generalized tonic-clonic or myoclonic convulsions occur mainly during non REM sleep and “drowsy wakefulness“ (Bazil, 2003, Janz, 1962). Epileptiform discharges are likely to propagate during non REM sleep, in particular in sleep stage two because the electroencephalographic (EEG) background activity is more synchronized with transients such as k-complexes and sleep spindles, and in transitional "drowsy" EEG arousal periods. In contrast the antiepileptic nature of REM sleep has been demonstrated in several reports linking sleep and epilepsy. The desynchronized low-amplitude activity during REM sleep decreases seizure susceptibility and 
those that do occur generalize in fewer cases (Bazil and Walczak, 1997, Malow et al., 1998, Shouse et al., 2000).

The antiepileptic effect of KD was very good in this study. At three months $44 \%$ and at twelve months $36 \%$ of the children had $>90 \%$ reduction in seizure frequency. The presumed antiepileptic effects of KD are increased cerebral energy reserves and decreased ictal excitability, decreased rate of glutamate transamination to aspartate and, possibly, enhancement in the rate of glutamate decarboxylation to GABA (Schwartzkroin, 1999, Stafstrom and Rho, 2004). The role of caloric restriction, direct anticonvulsant action of ketone bodies, polyunsaturated fatty acids, norepinephrine, galanin and neuropeptide Y (NPY) is also discussed (Stafstrom and Rho, 2004). Dahlin et al 2005 found, significantly increased GABA and decreased glutamate levels in CSF in a study of KD in children with refractory epilepsy (Kokaia et al., 2001). Galanin is a widespread neuropeptide in the CNS. It is found in many brain regions including hypothalamus, dorsal raphé nucleus (DR) and locus coeruleus (Bazil and Walczak). It is known to regulate food consumption, energy expenditure and pain, but also to decrease hippocampal excitability and glutamate release (Mazarati et al., 2000, Wang et al., 1998). Expression of galanin and NPY is shown to increase in starvation and high fat intake with decreased leptin and insulin levels, a situation identical to KD (Saper et al., 2005, Tempel et al., 1988). The dorsomedial hypothalamic nucleus (DMH) plays a role in the circadian control of sleep-wake cycling. It sends GABAergic projection to the sleep and REM promoting ventrolateral preoptic nucleus (VLPO) and promotes wakefulness via the ascending arousal system, among other cell-groups the monoaminergic DR and LC, and the lateral hypothalamic area (Touchon et al.) with stabilizing orexine/hypocretine influence (Saper et al., 2005). VLPO withhold sub-regions that are specialized for the control of REM versus nonREM via LC (Saper et al., 2001, Sherin et al., 1998). Since VLPO contains GABA and galanin, one could speculate that besides the anticonvulsant effects, the increase or 
normalization in REM sleep, of KD, is induced by changes in GABAergic and galaninergic functioning.

In conclusion, in our study, KD decreases sleep and improves sleep quality and in particular increases REM sleep, in children with therapy resistant epilepsy. We also see an improvement in seizure frequency, seizure severity, attentional behaviour and QOL and a significant correlation between increased REM sleep and QOL at three months. 
Acknowledgments

This research was supported by the Linnéa and Josef Carlsson Foundation, the Margaretahemmets Foundation, the Stiftelsen Samaritens Foundation, the Segerfalk Foundation and the Swedish Research Council \#84. We are grateful to EEG-technicians Inger Nordlund and Eva-Karin Olsson and Melinda Vysehrad for taking care of the recordings in many of the children in this study. We thank statistical consultant Jonas Björk, and Petter Jarbo for technical support. 
References

Achenbach, T. (1991) Manual for the Child Behaviour Checklist/4-8 and 1991 profile, Vermont, University of Vermont, Department of Psychiatry.

Bazil, C. W. (2003) Epilepsy and sleep disturbance. Epilepsy Behav, 4 Suppl 2, S39-45.

Bazil, C. W. \& Walczak, T. S. (1997) Effects of sleep and sleep stage on epileptic and nonepileptic seizures. Epilepsia, 38, 56-62.

Borbely, A. A. \& Achermann, P. (1999) Sleep homeostasis and models of sleep regulation. J Biol Rhythms, 14, 557-68.

Cortesi, F., Giannotti, F. \& Ottavioni, S. (1999) Sleep problems and daytime behavior in childhood idiopathic epilepsy. Epilepsia, 40, 1557-65.

Crespel, A., Coubes, P. \& Baldy-Moulinier, M. (2000) Sleep influence on seizures and epilepsy effects on sleep in partial frontal and temporal lobe epilepsies. Clin Neurophysiol, 111 Suppl 2, S54-9.

Finelli, L. A., Borbely, A. A. \& Achermann, P. (2001) Functional topography of the human nonREM sleep electroencephalogram. Eur J Neurosci, 13, 2282-90.

Freeman, J., Kelly, M. \& Freeman, J. (1994) The Epilepsy Diet Treatment: An Introduction to the Ketogenic Diet, New York, Demos.

Freeman, J. M., Vining, E. P., Pillas, D. J., Pyzik, P. L., Casey, J. C. \& Kelly, L. M. (1998) The efficacy of the ketogenic diet-1998: a prospective evaluation of intervention in 150 children. Pediatrics, 102, 1358-63.

Geyelin, H. (1921) Fasting as a method for treating epilepsy. Med Rec, 99, 1037-9.

Hallbook, T., Lundgren, J., Kohler, S., Blennow, G., Stromblad, L. G. \& Rosen, I. (2005) Beneficial effects on sleep of vagus nerve stimulation in children with therapy resistant epilepsy. Eur J Paediatr Neurol, 9, 399-407.

Janz, D. (1962) The grand mal epilepsies and the sleeping-waking cycle. Epilepsia, 3, 69-109.

Kokaia, M., Holmberg, K., Nanobashvili, A., Xu, Z. Q., Kokaia, Z., Lendahl, U., Hilke, S., Theodorsson, E., Kahl, U., Bartfai, T., Lindvall, O. \& Hokfelt, T. (2001) Suppressed kindling epileptogenesis in mice with ectopic overexpression of galanin. Proc Natl Acad Sci U S A, 98, 14006-11.

Lefevre, F. \& Aronson, N. (2000) Ketogenic diet for the treatment of refractory epilepsy in children: A systematic review of efficacy. Pediatrics, 105, E46.

Malow, B. A., Lin, X., Kushwaha, R. \& Aldrich, M. S. (1998) Interictal spiking increases with sleep depth in temporal lobe epilepsy. Epilepsia, 39, 1309-16.

Mazarati, A. M., Hohmann, J. G., Bacon, A., Liu, H., Sankar, R., Steiner, R. A., Wynick, D. \& Wasterlain, C. G. (2000) Modulation of hippocampal excitability and seizures by galanin. J Neurosci, 20, 6276-81.

Mendez, M. \& Radtke, R. A. (2001) Interactions between sleep and epilepsy. J Clin Neurophysiol, 18, 106-27.

O'Donghue, M. F., Duncan, J. S. \& Sander, J. W. (1996) The National Hospital Seizure Severity Scale: a further development of the Chalfont Seizure Severity Scale. Epilepsia, 37, 563-71.

Ohayon, M. M., Carskadon, M. A., Guilleminault, C. \& Vitiello, M. V. (2004) Meta-analysis of quantitative sleep parameters from childhood to old age in healthy individuals: developing normative sleep values across the human lifespan. Sleep, 27, 1255-73.

Ponsford, J. \& Kinsella, G. (1991) The Use of a Rating Scale of Attentional Behaviour. Neuropsychological Rehabilitation, 1, 241-257.

Pulsifer, M. B., Gordon, J. M., Brandt, J., Vining, E. P. \& Freeman, J. M. (2001) Effects of ketogenic diet on development and behavior: preliminary report of a prospective study. Dev Med Child Neurol, 43, 301-6. 
Rechtschaffen, A. \& Kales, A. (1968) A manual of standardized terminology, techniques and scoring system for sleep stage of human subjects. IN SERVICE, W. D. P. H. (Ed.), US Government Printing Office (National Institutes of Health Publication No.204).

Saper, C. B., Chou, T. C. \& Scammell, T. E. (2001) The sleep switch: hypothalamic control of sleep and wakefulness. Trends Neurosci, 24, 726-31.

Saper, C. B., Scammell, T. E. \& Lu, J. (2005) Hypothalamic regulation of sleep and circadian rhythms. Nature, 437, 1257-63.

Schwartzkroin, P. A. (1999) Mechanisms underlying the anti-epileptic efficacy of the ketogenic diet. Epilepsy Res, 37, 171-80.

Sherin, J. E., Elmquist, J. K., Torrealba, F. \& Saper, C. B. (1998) Innervation of histaminergic tuberomammillary neurons by GABAergic and galaninergic neurons in the ventrolateral preoptic nucleus of the rat. J Neurosci, 18, 4705-21.

Shouse, M. N., Da Silva, A. M. \& Sammaritano, M. (1996) Circadian rhythm, sleep, and epilepsy. J Clin Neurophysiol, 13, 32-50.

Shouse, M. N., Farber, P. R. \& Staba, R. J. (2000) Physiological basis: how NREM sleep components can promote and REM sleep components can suppress seizure discharge propagation. Clin Neurophysiol, 111 Suppl 2, S9-S18.

Stafstrom, C. E. \& Rho, J. M. (Eds.) (2004) Epilepsy and the Ketogenic Diet, Totowa, Humana Press.

Tempel, D. L., Leibowitz, K. J. \& Leibowitz, S. F. (1988) Effects of PVN galanin on macronutrient selection. Peptides, 9, 309-14.

Touchon, J., Baldy-Moulinier, M., Billiard, M., Besset, A. \& Cadilhac, J. (1991) Sleep organization and epilepsy. Epilepsy Res Suppl, 2, 73-81.

Wang, J., Akabayashi, A., Yu, H. J., Dourmashkin, J., Alexander, J. T., Silva, I., Lighter, J. \& Leibowitz, S. F. (1998) Hypothalamic galanin: control by signals of fat metabolism. Brain Res, 804, 7-20.

Wilder, R. (1921) The effects of ketonemia on the course of epilepsy. Mayo Clin Proc, 307-8. 
Figure 1, 2

Sleep Stage Report Before and After 3 months of Ketogenic Diet.

Patient 17 had the largest increase in REM-sleep (+61min,+21\%). His TNS was decreased (-242min), DS

unchanged, SWS decreased (-121min, $-4 \%$ ) and sleep stage 2 decreased (-122min, -17\%). At three months he was seizure free with $60 \%$ improvement in QOL. Behaviour and attention were unchanged.
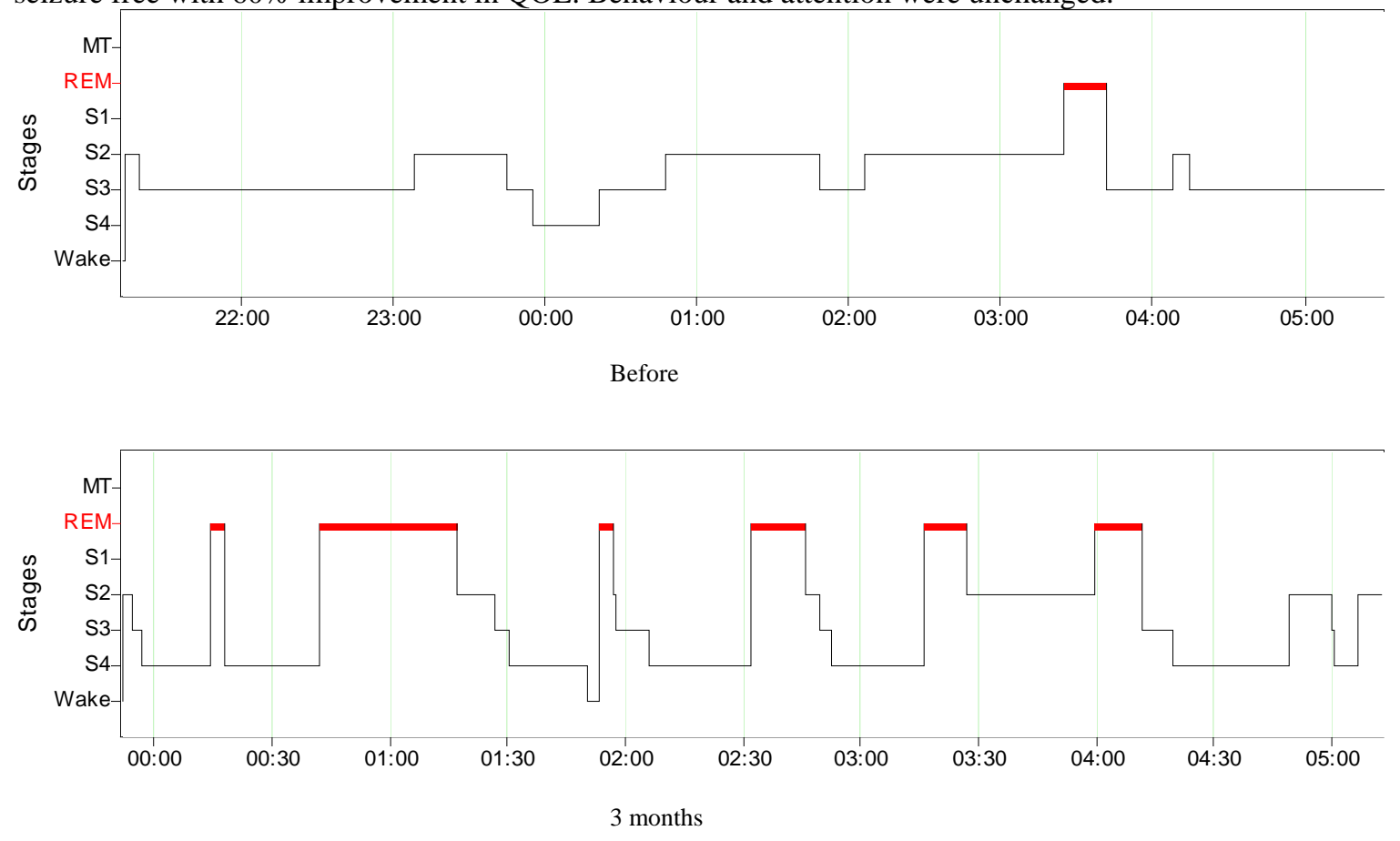

\section{Sleep Stage Report Before and After 3 months of Ketogenic Diet.}

Patient 3 had a large increase in REM-sleep (+75min, $+14 \%)$. His TNS was decreased (-40min), DS unchanged, SWS decreased (-61 min, -6\%) and sleep stage 2 decreased (-52min, -7\%). At three months he had a 75\% seizure reduction with $60 \%$ improvement in QOL. Behaviour and attention were also improved.
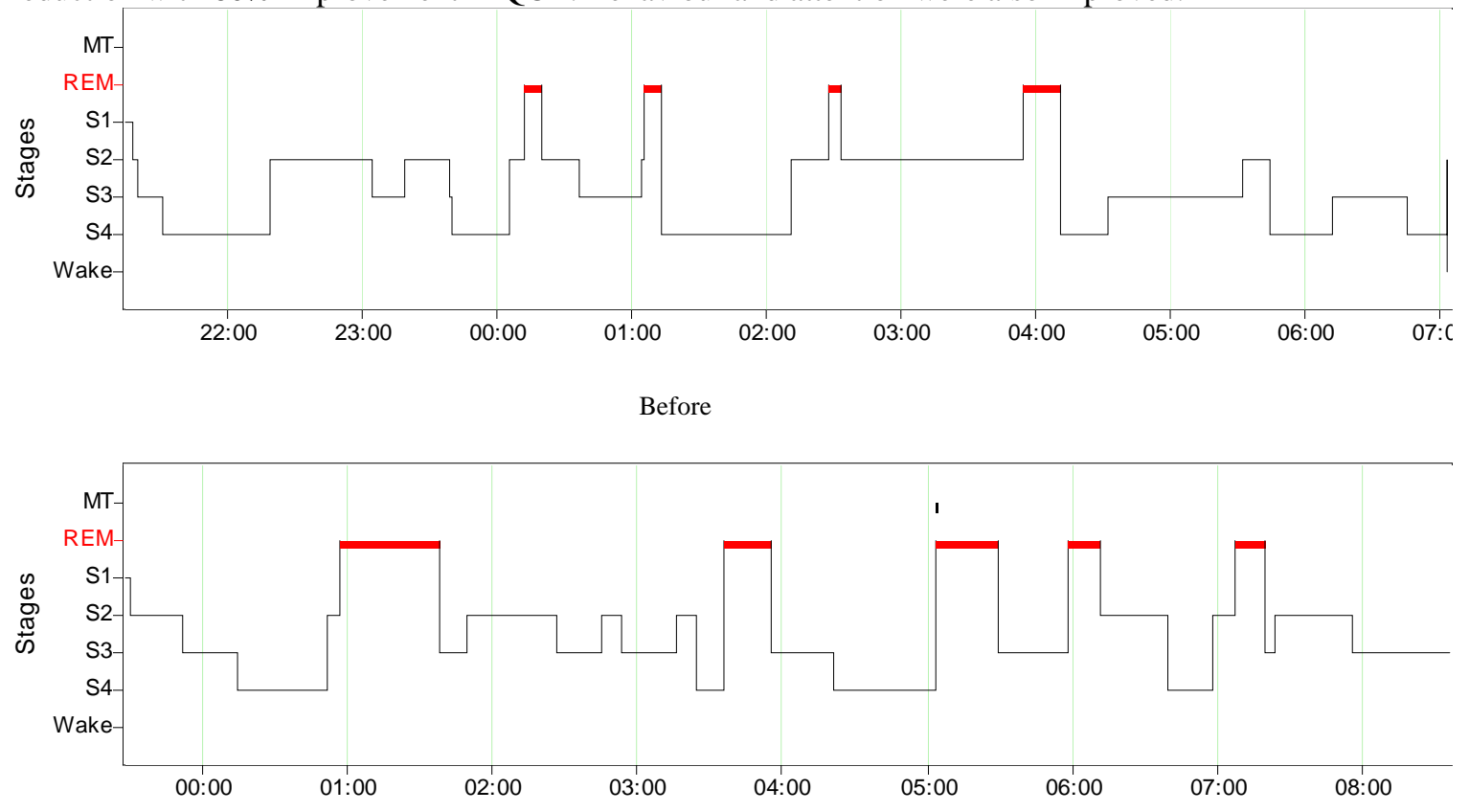
Table 1

\begin{tabular}{|c|c|c|c|c|c|c|c|c|c|}
\hline $\begin{array}{l}\text { Pat } \\
\text { No }\end{array}$ & $\begin{array}{l}\text { Age at } \\
\text { KD- } \\
\text { onset } \\
\text { (yr) } \\
\end{array}$ & $\begin{array}{l}\text { Age at } \\
\text { epilepsy } \\
\text { onset } \\
\text { (yr) }\end{array}$ & $\overline{\text { Etiology }}$ & $\begin{array}{l}\text { M } \\
\text { Ret }\end{array}$ & $\begin{array}{l}\text { Epilepsy } \\
\text { type/syndrome }\end{array}$ & AED & Seizure type & $\begin{array}{l}\text { Changes in } \\
\text { seizure frequency } \\
\text { at } 3 \text { months (\%) }\end{array}$ & $\begin{array}{l}\text { Changes in } \\
\text { seizure frequency } \\
\text { at } 12 \text { months (\%) }\end{array}$ \\
\hline 1 & 7 & 3 & Unknown & $\mathrm{M}$ & Generalized & SUX CLON & AD GTCS & Decreased 99\% & Decreased 99\% \\
\hline 2 & 14 & 5 & Unknown & M & MAE & $\begin{array}{l}\text { VPA LTG } \\
\text { CLON }\end{array}$ & Tonic/Gen & Decreased 90\% & Decreased $40 \%$ \\
\hline 3 & 2 & 0,13 & Unknown & S & IS, Lennox-G & $\begin{array}{l}\text { LTG Sulth } \\
\text { CLOB Nitra }\end{array}$ & AA GTCS & Decreased 72\% & Decreased 30\% \\
\hline 4 & 11 & 0,25 & Asphyxia & S & IS, Lennox-G & $\begin{array}{l}\text { LTG VPA } \\
\text { CLON }\end{array}$ & $\mathrm{TC} / 2^{\circ} \mathrm{GTCS}$ & Unchanged $0 \%$ & \\
\hline 5 & 5 & 2,5 & Encephalitis & $\mathrm{s}$ & Generalized, Lennox-G & OXC LTG & AA AD TD & Decreased 90\% & Decreased 89\% \\
\hline 6 & 4 & 0,75 & Unknown & Mild & Partial Cryptogenic & VPA CBZ & Tonic/Gen & Decreased 96\% & Decreased 90\% \\
\hline 7 & 8 & 5 & Unknown & $\mathrm{s}$ & Partial Cryptogenic & AZT & $\mathrm{TC} / 2^{\circ} \mathrm{GTCS}$ & Increased 50\% & \\
\hline 8 & 4 & Neonatal & Asphyxia & $\mathrm{s}$ & Gen & LTG Nitra & TD MC & Decreased 100\% & Decreased 80\% \\
\hline 9 & 5 & 2 & Encephalitis & $\mathrm{s}$ & Gen & VPA OXC & $\mathrm{TC} / 2^{\circ} \mathrm{GTCS}$ & Decreased 22\% & \\
\hline 10 & 9 & Neonatal & Asphyxia & S & IS, Partial Cryptogenic & $\begin{array}{l}\text { LTG GBP } \\
\text { CLOB }\end{array}$ & $\begin{array}{l}\text { Tonic/Gen } \\
\text { MC }\end{array}$ & Decreased 72\% & Decreased 85\% \\
\hline 11 & 5 & Neonatal & Asphyxia & $\mathrm{S}$ & IS, Partial Cryptogenic & $\begin{array}{l}\text { VGB VPA } \\
\text { CLON }\end{array}$ & AA TD MC & Decreased $40 \%$ & Decreased 88\% \\
\hline 12 & 3 & 0,67 & Unknown & $\mathrm{M}$ & Partial Cryptogenic & $\begin{array}{l}\text { LTG Sulth } \\
\text { CLOB }\end{array}$ & Tonic/Gen & Decreased 100\% & Decreased $100 \%$ \\
\hline 13 & 9 & Neonatal & Asphyxia & $\mathrm{s}$ & IS, Lennox-G & VPA Nitra & Tonic/Gen & Decreased 30\% & Decreased 37\% \\
\hline 14 & 9 & Neonatal & Unknown & $\mathrm{S}$ & Partial Cryptogenic & LTG TPA & $\mathrm{TC} / 2^{\circ} \mathrm{GTCS}$ & Decreased 80\% & \\
\hline 15 & 14 & 6 & Sp tumor, HC & $\mathrm{M}$ & Partial Symptomatic & OXC CLON & $\mathrm{TC} / 2^{\circ} \mathrm{GTCS}$ & Unchanged $0 \%$ & \\
\hline 16 & 13 & 2,5 & CMV & $\mathrm{S}$ & Partial Symptomatic & TPA & GTCS & Decreased 67\% & \\
\hline 17 & 6 & 1 & Asphyxia & S & Lennox-G & $\begin{array}{l}\text { LTG Sulth } \\
\text { CLOB }\end{array}$ & TD MC & Decreased $100 \%$ & Decreased $100 \%$ \\
\hline 18 & 15 & 0,5 & $\begin{array}{l}\text { Glut-1- } \\
\text { deficiency }\end{array}$ & M & Generalized & LTG & $\mathrm{AD}$ & Decreased $100 \%$ & \\
\hline
\end{tabular}

Abbreviations: AA, Atypical Absence; AD, Atonic Drop; AED, Anti Epileptic Drugs; AZT, Acetazolamide; CBZ; Carbamazepine; CLOB, Clobazepam; CLON,

Clonazepam; CMV, Cytomegalovirus; G, Gastaut; GBP, Gabapentin; Gen, Generalized; GTCS, Generalized Tonic Clonic Seizures; HC, Hydrocephalus; IS, Infantile Spasms; LTG, Lamotrigine; M, Moderate; MAE, Myoclonic Astatic Epilepsy; MC, Myoclonic; Mret, Mental retardation; Nitra, Nitrazepam; OXC, Oxcarbamazepine; S, Severe; Sp, Spinal; Sulth, Sulthiame; SUX, Suxinutin; TC, Tonic Clonic; TD, Tonic Drop; TPA, Topiramate; VPA, Valproate 
Table 2 Effects on sleep parameters, clinical seizures, seizure severity, quality of life, behavior, attention and beta hydroxybutyrate initially and after 3 months of ketogenic diet

\begin{tabular}{lll}
\hline & $\begin{array}{l}\text { Before KD } \\
\text { Median (range) }\end{array}$ & $\begin{array}{l}\text { After 3 months of KD } \\
\text { Median (range) / p }\end{array}$ \\
\hline TS (min) & $675,75(492,5-924)$ & $589,25(321,5-776) / 0,05$ \\
TNS (min) & $612,10(346,5-821)$ & $546,55(169-683) / 0,006$ \\
TDS (min) & $53,75(0-169,5)$ & $53,75(0-250) / 0,67$ \\
Stage 1 (min) & $0(0-8,5)$ & $0,75(0-5,5) / 0,48$ \\
Stage 1 (\%TNS) & $0(0-1,4)$ & $0,15(0-1,6) / 0,38$ \\
Stage 2 (min) & $195,25(49-497)$ & $141,75(20-346) / 0,002$ \\
Stage 2 (\%TNS) & $36,3(7,9-84,2)$ & $26,5(3,8-66) / 0,004$ \\
Stage 3+4 (min) & $274,25(27-613)$ & $278(25-463,5) / 0,5$ \\
Stage 3+4 (\%TNS) & $47,05(4,6-77,9)$ & $53,8(7,5-82,7) / 0,29$ \\
REM (min) & $86,5(17,5-189,5)$ & $97(42-197,5) / 0,23$ \\
REM (\%TNS) & $14,15(3,5-28,20)$ & $19,55(8-37,6) / 0,01$ \\
Stage shifts (n) & $33(12-44)$ & $28(16-44) / 0,59$ \\
Sleep latency (min) & $0,5(0-2)$ & $0,05(0-0,5) / 0,06$ \\
Clinical seizures & $75,3(1-21604)$ & $15,8(0-900) / 0,001$ \\
NHS3 & $12,5(3-31)$ & $6(1-19) /<0,001$ \\
QOL & $10(10-10)$ & $14(10-18) / 0,001$ \\
CBCL & $40(13-19)$ & $38(6-73) / 0,08$ \\
PK & $28(7-21)$ & $17(3-35) / 0,006$ \\
Beta hydroxybutyrate & $1(0,1-3,2)$ & $4,2(2,6-7,7) / 0,003$ \\
\hline
\end{tabular}

Abbreviations:

KD, Ketogenic diet; TS, Total sleep; TNS, Total night sleep; TDS, Day sleep; Stage 1,2,3+4, Sleep stage 1,2,3+4; REM, Rapid eye movement; NHS3, National health seizure severity scale; QOL, Quality of life; CBCL, Child behaviour checklist; PK, Ponsford and Kinsella's rating-scale of attentional behaviour

Table 3 Effects on sleep parameters, clinical seizures, seizure severity, quality of life, behavior, attention and beta hydroxybutyrate initially and after 3 and 12 months of ketogenic diet

\begin{tabular}{llll}
\hline 11 pat & $\begin{array}{l}\text { Before KD } \\
\text { Median (range) }\end{array}$ & $\begin{array}{l}\text { After } 3 \text { months of KD } \\
\text { Median (range) / p }\end{array}$ & $\begin{array}{l}\text { After 12 months of KD } \\
\text { Median (range) / p }\end{array}$ \\
\hline TS (min) & $657(492,5-924)$ & $588,5(321,5-766) / 0,08$ & $573(342-708,4) / 0,09$ \\
TNS (min) & $600,40(492-821)$ & $546,55(169-683) / 0,04$ & $573(342-708,4) / 0,5$ \\
TDS (min) & $62,5(0-118,5)$ & $53,75(0-250) / 0,58$ & $0(0-36) / 0,01$ \\
Stage 1 (min) & $0(0-8,5)$ & $1(0-2) / 1$ & $0(0-9) / 0,9$ \\
Stage 1 (\% TNS) & $0(0-1,4)$ & $0,2(0-0,4) / 0,86$ & $0(0-1,3) / 0,83$ \\
Stage 2 (min) & $188,5(120-497)$ & $141,75(20-346) / 0,05$ & $158(70,9-388,4) / 0,1$ \\
Stage 2 (\% TNS) & $37,1(14,7-84,2)$ & $26,5(3,8-66) / 0,05$ & $30.1(13,8-54,8) / 0,2$ \\
Stage 3+4 (min) & $294(27-613,5)$ & $278(25-463,5) / 0,37$ & $215(155-350,5) / 0,4$ \\
Stage 3+4 (\% TNS) & $54,1(4,6-74,8)$ & $53,8(7,5-82,7) / 0,8$ & $39.6(21,9-67) / 0,5$ \\
REM min & $69,5(17,5-117)$ & $97(42-197,5) / 0,18$ & $116(44-194) / 0,04$ \\
REM \% & $11,2(3,5-23,9)$ & $19,55(8-37,6) / 0,11$ & $20,2(9,9-36,9) / 0,06$ \\
Stage shifts (n) & $28(12-42)$ & $28(16-44) / 0,76$ & $37(24-50) / 0,3$ \\
Sleep latency (min) & $0,5(0-2)$ & $0,1(0-0,5) / 0,13$ & $0(0-116,5) / 0,2$ \\
Clinical seizures & $122,6(58-21604)$ & $22(0-900) / 0,002$ & $49,6(0-180) / 0,003$ \\
NHS3 & $12(3-31)$ & $5(1-11) / 0,005$ & $5(1-14) / 0,005$ \\
QOL & $10(10-10)$ & $15(12-16,5) / 0,003$ & $16(12-20) / 0,005$ \\
CBCL & $39(13-61)$ & $36(6-67) / 0,18$ & $34,5(10-66) / 0,54$ \\
PK & $27(7-36)$ & $17(3-28) / 0,03$ & $15(0-38) / 0,08$ \\
Beta hydroxybutyrate & $1(0,1-3,2)$ & $4,2(2,6-7,7) / 0,003$ & $5,2(2,7-7,2) / 0,003$ \\
\hline Abbing
\end{tabular}

Abbreviations:

KD, Ketogenic diet; TS, Total sleep; TNS, Total night sleep; TDS, Day sleep; Stage 1,2,3+4, Sleep stage 1,2,3+4; REM, Rapid eye movement; NHS3, National health seizure severity scale; QOL, Quality of life; CBCL, Child behaviour checklist; PK, Ponsford and Kinsella's rating scale of attentional-behaviour 